\title{
Alfabetização científica no ensino de ciências nos anos iniciais do ensino fundamental: percepções de professores da rede municipal de ensino de Curitiba
}

Lucimara Fabricio lucimara fabricio@yahoo.com.br orcid.org/0000-0001-5347-3993 Paraná (UTFPR), Curitiba, Paraná, Brasil

\section{Alisson Antonio Martins} amartins@utfpr.edu.br https://orcid.org/0000-0002-4431-2247. Universidade Tecnológica Federal do Paraná (UTFPR), Curitiba, Paraná, Brasi.

\begin{abstract}
RESUMO
Neste trabalho apresentam-se os resultados de uma pesquisa desenvolvida junto a professoras dos anos iniciais do Ensino Fundamental de escolas públicas de Curitiba, Paraná, na temática da alfabetização científica que, de acordo com Shen (1975), possibilita um maior entendimento público da Ciência e uma desmistificação do conhecimento científico para que as pessoas possam utilizá-los em suas vidas cotidianas. Essas premissas estão sendo contempladas pelo Currículo do Ensino Fundamental - 1으 ao 9ㅇan anolume IV, referente às Ciências Naturais, da Prefeitura Municipal de Curitiba, que é o documento que orienta o planejamento escolar dos professores de Ciências Naturais das escolas públicas municipais. No entanto, é necessário, para além do que se apresenta no documento oficial, conhecer o que pensam os professores que atuam nessas escolas. Deste modo, esta investigação, de natureza qualitativa e de cunho descritivo e interpretativo, foi norteada pelo seguinte problema de pesquisa: quais são as percepções de professores sobre o processo de ensino-aprendizagem de Ciências Naturais na perspectiva da alfabetização científica? Como percursos metodológicos, foram utilizados questionários $(n=45)$ e entrevistas semiestruturadas $(n=10)$, por meio dos quais se objetivou investigar as percepções de professores sobre o processo de ensinoaprendizagem de Ciências Naturais para os anos iniciais do Ensino Fundamental. Os resultados da investigação mostraram que a concepção de Ciências das participantes da pesquisa tendeu para a noção de alfabetização científica prática, numa perspectiva de um ensino de Ciências voltado às compreensões básicas da área, tais como o uso dos conceitos científicos no dia a dia e na preservação do meio ambiente; relacionar a aprendizagem de Ciências com as necessidades básicas, como alimentação, saúde e a melhorar a qualidade de vida. As outras proposições do Currículo Municipal, isto é, aquelas relativas a alfabetização científica em suas dimensões cívica e cultural são menos desenvolvidas, havendo uma predominância, portanto, da dimensão prática, enquanto expressão de uma série de fatores, como por exemplo a formação inicial generalista, o modo de organização dos livros didáticos para estes anos de escolaridade, baixa adesão às formações continuadas, entre outros aspectos. Os dados construídos nesta investigação apontam para uma necessidade de se repensar os objetivos e as práticas desenvolvidas no ensino de Ciências nos anos iniciais do Ensino Fundamental, para que seja possível o desenvolvimento de um processo de alfabetização científica e, assim, sejam preenchidas as lacunas que existem na compreensão dessa abordagem. Ressalta-se também, a necessidade de pesquisas e contínuo processo de formação docente como forma de aproximações teórico-metodológicas levando-se em consideração a realidade escolar, suas necessidades e a experiência profissional docente.
\end{abstract}

PALAVRAS-CHAVE: Ciências da Natureza. Alfabetização científica. Currículo. Ensinoaprendizagem. 


\section{INTRODUÇÃO}

Nas últimas décadas, a discussão sobre uma necessária renovação do Ensino de Ciências em todos os níveis de Educação Básica tem estado presente em diversas pesquisas e referenciais teóricos que procuram refletir sobre uma educação crítica, transformadora e que tenha no conhecimento científico o alicerce para a problematização da realidade social (CACHAPUZ et al., 2011; SILVA; SÁ; BATINGA, 2019; SOLINO; FERRAZ; SASSERON, 2015). O modo de se relacionar com os conhecimentos cotidianos e com aqueles advindos da Ciência, por meio da alfabetização científica, requer um ensino que contemple sua construção desde os anos iniciais do Ensino Fundamental.

Para validar a importância da alfabetização científica, na perspectiva do letramento científico por meio do contexto social, a Declaração de Budapeste (1999) traz uma série de afirmações que buscam justificar que um país que queira ter condições mínimas para atender às necessidades fundamentais de uma população precisa investir no ensino de Ciências e Tecnologia, ou seja, difundir a alfabetização científica em todos os níveis de educação e setores da sociedade. De acordo com Shen (1975), a alfabetização científica contempla um maior entendimento público da Ciência e uma desmistificação do conhecimento científico para que as pessoas possam utilizá-los em sua vida cotidiana.

Nesse contexto, as escolas cumprem um papel fundamental, contribuindo para que a população se aproprie dos conhecimentos da Ciência e participe de debates democráticos sobre questões que envolvam assuntos relacionados à Ciência e à Tecnologia. Para isso, o ensino de Ciências que ocorre no contexto escolar deve envolver um conjunto de fatos, vocábulos, conceitos, história e filosofia que são próprios do conhecimento científico.

Deste modo, é necessário que o ensino de Ciências seja de qualidade desde os anos iniciais. Neste sentido, o processo de alfabetização científica, além de trazer benefícios para a aquisição da leitura e da escrita, pode instrumentalizar o estudante para atuar no processo de construção do seu entendimento sobre os fenômenos da natureza, auxiliando-o a fazer uma leitura mais objetiva do mundo que o cerca.

Considerando-se que o ensino de Ciências possui um compromisso científico e social, um nível baixo de letramento impacta na formação dos indivíduos e, consequentemente, em seu cotidiano, como mostram os dados do índice de Letramento Científico (ILC) da população brasileira, ou seja, uma precária escolarização básica com ausência de aporte científico para a atuação nas diferentes esferas da sociedade (GOMES, 2015).

Nas últimas décadas, autores como Lorenzetti e Delizoicov (2001), Briccia e Carvalho (2016) e Sasseron (2015) vêm destacando a importância da introdução ao conhecimento e pensamento científico, da experimentação e da problematização nas aulas de Ciências para tornar os alunos cidadãos críticos, criativos e coautores de seu aprendizado com autonomia para realizar decisões inteligentes e para resolver situações comuns de seu cotidiano.

Dada essa importância, essas premissas estão sendo contempladas pelos documentos oficiais, como o Currículo Municipal de Ciências Naturais do 10 ao 5o ano do Ensino Fundamental da Prefeitura Municipal de Curitiba, que é o 
documento que orienta o planejamento escolar dos professores de Ciências Naturais das escolas públicas municipais do referido município.

A partir destas reflexões, este artigo apresenta os resultados de uma investigação de natureza qualitativa e de cunho descritivo e interpretativo, desenvolvida junto a professores dos anos iniciais do Ensino Fundamental da rede municipal de Curitiba (PR), cujo objetivo geral foi compreender as percepções de professores sobre o processo de ensino-aprendizagem de Ciências Naturais na perspectiva da alfabetização científica.

\section{ALFABETIZAÇÃO CIENTÍFICA: ELEMENTOS TEÓRICOS}

De acordo com Sasseron e Carvalho (2011), a alfabetização científica (AC) é um conceito que surgiu no Século XX, especificamente na década de 1950, com o professor americano Paul Dehart Hurd (1905-2001), considerado o primeiro pesquisador a utilizar o termo "Scientific Literacy". Esta expressão aparece no livro de sua autoria "Science Literacy: Its Meaning for American Schools", publicado em 1958 e é utilizada como referência aos pesquisadores da área.

Nos referenciais teóricos, encontram-se autores que adotam diferentes traduções para "Scientific Literacy", tais como alfabetização científica, (Lorenzetti, 2000) alfabetização científica e tecnológica (Bocheco, 2011) letramento científico (Santos e Mortimer, 2001) ou enculturação científica (Sasseron e Carvalho, 2011). Independentemente do termo utilizado, estes autores convergem sobre a necessidade de proporcionar um modelo de ensino que possibilite aos estudantes compreender o conhecimento científico e intervir na sociedade atual.

Os trabalhos que se inserem na temática da AC têm destacado que o ensino de ciências não deve se preocupar somente com a escrita e a memorização de conceitos científicos, como a praticada no contexto de uma abordagem tradicional (MIKUZAMI, 1986), mas deve estar atenta a outros fatores como, por exemplo, as implicações sociais e ambientais dos benefícios e dos riscos de cada avanço científico ou tecnológico. Dentro dessa concepção, Laugksch (2000) apresentou sete dimensões para a AC: (1) a compreensão do conhecimento científico; (2) a aplicação correta dos conceitos científicos na interação com seu universo; (3) o uso da ciência na resolução de problemas e tomada de decisões; (4) o conhecimento dos valores que fundamentam a ciência; (5) a compreensão das relações entre ciência, tecnologia e sociedade; (6) o desenvolvimento de uma visão integrada do universo resultante da sua educação em ciência e (7) a ampliação de inúmeras competências associadas com a ciência e a tecnologia.

De acordo com Bocheco (2011), os conteúdos desenvolvidos em sala de aula devem ser trabalhados sob as abordagens de parâmetros de AC, evitando-se, assim, que o ensino em sala de aula recaia em desequilíbrios gerados pela necessidade de contextualização e sobreposição de disciplinas de forma equivocada ou supérflua.

Para Shen (1975), a alfabetização científica pode ser compreendida a partir de três dimensões: AC prática, AC cívica e a AC cultural, sintetizados no Quadro 1. 
Quadro 1 - Dimensões da Alfabetização Científica para Shen (1975)

\begin{tabular}{|c|c|}
\hline Dimensão & Características \\
\hline Prática & $\begin{array}{l}\text { Está relacionada com as necessidades humanas básicas como } \\
\text { alimentação, saúde e habitação, instrumentalizando o cidadão na } \\
\text { resolução de problemas substanciais que afetam a sua vida, } \\
\text { proporcionando "um tipo de conhecimento científico e técnico } \\
\text { que pode ser posto em uso imediatamente, para ajudar a } \\
\text { melhorar os padrões de vida" (p. 265). Essa dimensão da AC deve } \\
\text { ser promovida nas escolas, ampliada em outros espaços não } \\
\text { formais de ensino e disseminada pelos meios de comunicação. }\end{array}$ \\
\hline Cívica & $\begin{array}{l}\text { Diz respeito às tomadas de decisões pelos cidadãos, estando } \\
\text { relacionadas com a Ciência e seus problemas, na medida em que } \\
\text { contribui para "torná-lo mais informado sobre a Ciência e as } \\
\text { questões relacionadas a ela, de modo que ele e seus } \\
\text { representantes possam trazer seu senso comum para apreciá-lo } \\
\text { e, desta forma, participar mais intensamente no processo } \\
\text { democrático de uma sociedade crescentemente tecnológica" (p. } \\
\text { 266). }\end{array}$ \\
\hline Cultural & $\begin{array}{l}\text { Nesta dimensão, a AC “é motivada por um desejo de saber algo } \\
\text { sobre ciência, como uma realização humana fundamental; [...] } \\
\text { Ela não resolve nenhum problema prático diretamente, mas } \\
\text { ajuda a abrir caminhos para a ampliação entre as culturas } \\
\text { científicas e humanísticas" (p. 267). Este tipo de AC é procurado } \\
\text { por uma pequena parcela da população que deseja aprofundar } \\
\text { seus conhecimentos sobre um determinado assunto científico } \\
\text { que seja de seu interesse. Assim, o cidadão buscará meios para } \\
\text { compreender, discutir e posicionar-se em relação aos } \\
\text { conhecimentos envolvendo a Ciência. }\end{array}$ \\
\hline
\end{tabular}

Fonte: Adaptado de Shen (1975).

De acordo com Lorenzetti (2000) a alfabetização científica é a capacidade de compreensão e interpretação dos conhecimentos científicos, assim como a formulação de ideias científicas em uma variedade de contextos, inclusive os cotidianos. Essa variedade de contextos transcende o espaço escolar para outros espaços educativos, tais como museus, clubes, teatros, leituras, entre outros.

As dimensões apresentadas por Shen (1975) têm sido utilizadas de formas distintas, pelos autores da área, auxiliando os professores, em contexto escolar, nos processos de mapeamento, de compreensão e de definição de conceitos científicos, discutindo sua importância para a educação em Ciências. Neste sentido, Lorenzetti, Siemsen e Oliveira (2017) abordam o potencial de livros didáticos de Química, na temática de ácidos e bases, no contexto da alfabetização científica e tecnológica. Outro exemplo de utilização deste referencial se encontra no trabalho de Siemsen (2019), em que a autora analisa as potencialidades de uma sequência didática, utilizando os parâmetros de alfabetização científica.

Nesta perspectiva, para além da escrita e da memorização de conceitos científicos, o ensino de Ciências nos anos iniciais do Ensino Fundamental teria a possibilidade de discutir e promover reflexões sobre os fatores relacionados às implicações sociais e ambientais dos benefícios e dos riscos associados a cada avanço científico ou tecnológico. 


\section{ORIENTAÇÕES CURRICULARES PARA OS ANOS INICIAIS NO MUNICÍPIO DE CURITIBA}

O Currículo do Ensino Fundamental Municipal de Curitiba (CURITIBA, 2016) foi reformulado e construído coletivamente com a participação de profissionais da área, entre 2013-2016, entrando em vigor a partir do ano letivo de 2017. Nesse documento, que gerencia as ações pedagógicas desenvolvidas nas unidades escolares, nos anos iniciais do Ensino Fundamental, foram reavaliados os conteúdos, os objetivos e os critérios de avaliação para cada ano. As mudanças foram coordenadas pelo Departamento de Ensino Fundamental da Secretaria Municipal de Educação (SME) com o objetivo de atualizar as propostas pedagógicas que estavam vigentes desde 2006.

O Currículo Municipal, assim como os projetos pedagógicos das escolas devem conter os conhecimentos, as competências e as habilidades definidas na Base Nacional Comum Curricular (BNCC). Segundo esse documento (BRASIL, 2017) a área de Ciências da Natureza tem um compromisso pautado no letramento científico, de acordo com a BNCC (p. 321), tal compromisso envolve a capacidade de compreender e interpretar o mundo (natural, social e tecnológico), mas também de transformá-lo com base nos aportes teóricos e processuais das ciências. (p. 321)

Para o aluno ter acesso a essa diversidade de conhecimentos, o Currículo Municipal está organizado em conteúdos por anos e em quatro eixos: Vida e Ambiente, Ser Humano e Saúde, Matéria e Energia e Terra e Universo. Esses eixos devem estar articulados com as áreas que formam o componente curricular das Ciências, que são os conhecimentos advindos da Física, Biologia e da Química.

O Currículo Municipal de Curitiba está pautado na alfabetização científica, na perspectiva do letramento científico, assim definido:

\footnotetext{
A principal finalidade deste documento é proporcionar aos (às) estudantes a alfabetização científica, utilizando o conhecimento científico como ferramenta de leitura de mundo, a fim de que eles (as) compreendam a natureza da Ciência e a influência dos avanços científicos e tecnológicos na sociedade (CURITIBA, 2016, p. 5).
}

O documento supracitado está baseado numa linha de pensamento fundamentada na alfabetização científica, ou seja, no entendimento da ciência como uma atividade humana e socialmente construída, na formação cidadã de seus estudantes para o domínio e uso de conhecimentos com base científica para que possam utilizar esses conhecimentos em diferentes situações e momentos de suas vidas ao conceber os conceitos científicos como parte de nossa cultura. Assim, esse documento concebe o ensino de Ciências como uma atividade humana, social e historicamente construída, considerando a construção do conhecimento de forma sistemática, porém, passível de verificação a fim de se compreender a realidade.

Deste modo, a organização dos eixos no Currículo de Ciências leva em consideração a compreensão básica dos termos, conhecimentos e conceitos científicos fundamentais, além de fatores éticos e políticos que circulam a sua prática e os entendimentos relativos às questões da Ciência, Tecnologia, considerações a respeito do uso de determinadas metodologias, buscando 
privilegiar as que evidenciam a problematização, a contextualização e a investigação dos fenômenos naturais que contribuam para o acesso aos saberes científicos.

\section{PROCEDIMENTOS METODOLÓGICOS}

Esta pesquisa, de natureza qualitativa e de cunho descritivo e interpretativo, contempla uma abordagem de investigação que dá ênfase à descrição, à interpretação e ao estudo das percepções de seus participantes (BOGDAN; BIKLEN, 1994). Seu desenvolvimento ocorreu mediante autorização do Parecer $n$ ㅇ 2.598.861 do Comitê de Ética em Pesquisa com Seres Humanos da UTFPR.

Para a construção dos dados foram enviados questionários às escolas da Rede Municipal de Educação de Curitiba, que atendem do 1으 ao 5ㅇa ano, obtendose um retorno de quarenta e cinco questionários respondidos. Na sequência, foram realizadas entrevistas semiestruturadas com dez professoras de Ciências que atuavam nas escolas em que os questionários foram aplicados. Visando obter uma multiplicidade de visões sobre as possibilidades de desenvolvimento da alfabetização científica, as dez escolas foram selecionadas aleatoriamente mediante a alternância entre as regulares e as de período integral e com distintos valores no Índice de Desenvolvimento da Educação Básica (IDEB). O convite às professoras para as entrevistas ocorreu por meio de indicação da direção da escola selecionada e das disposições voluntárias das professoras em participar da investigação.

As questões contidas no questionário foram organizadas em dois blocos: o primeiro visou conhecer o perfil dos professores, com perguntas tais como a idade, a formação, o tempo de serviço, etc.; o segundo bloco foi referente ao ensino e aprendizagem em Ciências, com considerações sobre a importância do ensino de Ciências na escola, quais recursos e estratégias são utilizados no dia a dia, se os professores frequentam os cursos de formação continuada, etc. Já nas entrevistas, o objetivo foi aprofundar as mesmas questões respondidas no questionário e oportunizar às professoras uma oportunidade para apresentarem suas percepções sobre o ensino de Ciências.

Estes instrumentos de pesquisa permitiram conhecer as percepções dos professores sobre o ensino e a aprendizagem de Ciências para alunos dos anos iniciais do Ensino Fundamental. A análise dos dados é empírica-interpretativa, pois, procurou-se, na diversidade de dados produzidos, a construção de significados que permitissem gerar novas reflexões e discussões para o problema pesquisado (CRESWELL, 2007).

A intenção foi gerar reflexões e discussões ao problema pesquisado para, deste modo, propor reflexões sobre a formação de professores de Ciências que atuam nos anos iniciais do Ensino Fundamental.

\section{RESULTADOS}

Num primeiro momento de desenvolvimento da pesquisa, os questionários permitiram estabelecer alguns elementos de caracterização dos participantes. 
Quanto à idade das professoras participantes da pesquisa, atuantes na Rede Municipal de Educação de Curitiba (RME), verificou-se a seguinte distribuição: $2,5 \%$ estão com menos de 25 anos de idade; $27,5 \%$ com idade entre 25 e 29 anos; $32,5 \%$ entre 30 e 39 anos; $30 \%$ entre 40 e 49 anos e 7,5\% entre 50 e 59 anos.

Identificou-se que as professoras possuem como nível mais alto de formação o mestrado, porém, a maioria delas possui especialização (Quadro 2).

Quadro 2 - Nível mais alto de formação das professoras participantes

\begin{tabular}{|c|c|}
\hline Formação & Porcentagem \\
\hline Pedagogia & $15 \%$ \\
\hline Outra licenciatura & $5 \%$ \\
\hline Outros cursos de educação superior & $2,5 \%$ \\
\hline Especialização & $75 \%$ \\
\hline Mestrado & $2,5 \%$ \\
\hline
\end{tabular}

Fonte: Autoria própria (2019).

O Quadro 3 sintetiza as informações relativas ao tempo de atuação dos professores na rede.

Quadro 3 - Tempo de atuação profissional dos professores na mesma escola

\begin{tabular}{|c|c|}
\hline Tempo de atuação na mesma escola & Porcentagem \\
\hline Menos de 1 ano & $2,5 \%$ \\
\hline 1 a 2 anos & $7,5 \%$ \\
\hline 3 a 5 anos & $40 \%$ \\
\hline 6 a 10 anos & $27,5 \%$ \\
\hline 11 a 15 anos & $17,5 \%$ \\
\hline 16 a 20 anos & $5 \%$ \\
\hline
\end{tabular}

Fonte: Autoria própria (2019).

No contexto da caracterização das professoras entrevistadas, elas possuem entre 29 e 68 anos, com média de aproximadamente 12 anos de experiência no Ensino Fundamental 1. Com relação à formação acadêmica, predominantemente, as participantes possuem especialização, com exceção de P2 e uma profissional que possui mestrado (P3), conforme indicado no Quadro 4. Os códigos utilizados visam resguardar a identidade e a privacidade de cada professora, conforme orientação do Comitê de Ética em Pesquisa com Seres Humanos.

Quadro 4 - Caracterização das professoras entrevistadas

\begin{tabular}{|c|c|c|}
\hline Professora & Idade (anos) & Experiência (anos) \\
\hline P1 & 49 & 6 \\
\hline P2 & 41 & 14 \\
\hline P3 & 48 & 28 \\
\hline P4 & 35 & 6 \\
\hline P5 & 29 & 6 \\
\hline P6 & 68 & 15 \\
\hline P7 & 43 & 14 \\
\hline P8 & 39 & 12 \\
\hline P9 & 38 & 11 \\
\hline P10 & 42 & 13 \\
\hline
\end{tabular}

Fonte: Autoria própria (2019). 
A análise das informações fornecidas nos questionários e nas entrevistas permitiu identificar particularidades sobre a importância de se ensinar Ciências nos anos iniciais sob a ótica da alfabetização científica e dos referenciais curriculares do município.

Com o objetivo de sistematizar e de apresentar de que modo estas informações foram analisadas nesta pesquisa, optou-se por uma apresentação baseada nas perguntas formuladas nos instrumentos de pesquisa.

Deste modo, uma das questões da entrevista procurou analisar de que modo os professores consideravam a importância de se ensinar Ciências na escola. De acordo com a proposta investigativa, esta pergunta poderia contribuir para a identificação de mitos e de equívocos comuns entre professores sobre o ensino de Ciências e fazer com que os professores compreendessem que suas concepções sobre Ciências influenciam nas aprendizagens dos alunos.

Para as docentes entrevistadas, quando questionadas sobre suas percepções sobre o ensino de Ciências nos anos iniciais, percebeu-se que, embora essas professoras não possuam formação específica na área, prevaleceram em suas palavras, compreensões das proposições da alfabetização científica conforme as noções de propostas por Shen (1975), isto é, Alfabetização Científica Prática, Cívica e Cultural. A partir dessas percepções, essas compreensões foram classificadas de acordo com os parâmetros propostos por Shen (1975) apresentado no Quadro 5.

Quadro 5 - Compreensões dos professores sobre sua disciplina

\begin{tabular}{|c|c|c|c|}
\hline Profissionais & AC Prática & AC Cívica & AC Cultural \\
\hline P1 & $*$ & $*$ & $*$ \\
P2 & $*$ & $*$ & $*$ \\
P3 & $*$ & & \\
P4 & $*$ & & \\
P5 & $*$ & & \\
P6 & $*$ & & \\
P7 & $*$ & & \\
P8 & $*$ & & \\
P9 & $*$ & & \\
P10 & & & \\
\hline
\end{tabular}

Fonte: Autoria própria (2018).

Por meio da análise, considera-se que as participantes da pesquisa percebem, no ensino de Ciências, as compreensões básicas da área, prevalecendo a noção de alfabetização científica prática, ou seja, o uso dos conceitos científicos no dia-a-dia e na preservação do meio ambiente e a relação entre a aprendizagem de Ciências e o atendimento de necessidades básicas, como alimentação, saúde e a melhoria à qualidade de vida.

No Quadro 6 estão sintetizadas as respostas das participantes que mostram a prevalência da AC Prática em suas falas. 
Quadro 6 - Classificação das respostas, segundo os parâmetros de AC Prática.

\begin{tabular}{|c|c|}
\hline Professoras & Alfabetização Científica Prática \\
\hline P1 & $\begin{array}{c}\text { Acho muito importante o ensino de Ciências nas escolas, pois os } \\
\text { conteúdos trabalhados são bastante interessantes, chama a atenção } \\
\text { dos alunos e desperta o interesse pelas Ciências, também muito dos } \\
\text { conteúdos fazem parte do cotidiano deles e o estudo das ciências pode } \\
\text { ajudar a melhorar a qualidade de vida (...) }\end{array}$ \\
\hline P2 & $\begin{array}{c}\text { É importante para o estudante aprender a pensar sobre como funciona } \\
\text { tudo a seu redor, compreender o mundo como um todo. (...) Entender } \\
\text { que as coisas estão diferentes de como era antigamente. Compreender } \\
\text { sobre a consciência da preservação do nosso ambiente em que } \\
\text { vivemos. }\end{array}$ \\
\hline P3 & $\begin{array}{c}\text { A importância de ensinar Ciências nas escolas, eu acredito que é de } \\
\text { facilitar as alternativas metodológicas, para despertar e atrair o } \\
\text { interesse dos alunos em Ciências, (...) }\end{array}$ \\
\hline P4 & $\begin{array}{l}\text { Assim como as outras áreas do conhecimento, Ciências também é um } \\
\text { conhecimento formal e deve ser valorizado na escola que é uma } \\
\text { instituição de educação formal. Então, a Língua Portuguesa vai ajudar } \\
\text { na interpretação, leitura e escrita e as aulas de Ciências são } \\
\text { fundamentais para esclarecer para as crianças os conteúdos } \\
\text { relacionados aos aspectos de Ciências Naturais, Biologia, conhecimento } \\
\text { dos animais, das plantas, alguns aspectos da tecnologia, alimentação, } \\
\text { etc. Isso é o que eu mais atuo com eles, que é o 5o ano, então, eu acho } \\
\text { que tem importância tanto quanto os outros, outras áreas, já } \\
\text { estabelecidas na escola. }\end{array}$ \\
\hline P5 & $\begin{array}{l}\text { Porque nas aulas de Ciências, os alunos aprendem sobre tudo que os } \\
\text { rodeia: meio ambiente, corpo humano, astronomia, alimentação, } \\
\text { etc.(...) }\end{array}$ \\
\hline P6 & $\begin{array}{l}\text { Eu acho muito importante para eles, pois é sobre a vida deles, o seu } \\
\text { cotidiano. }\end{array}$ \\
\hline P7 & $\begin{array}{l}\text { É uma disciplina diferente das outras porque traz mais elementos do } \\
\text { cotidiano deles. Ciências ajuda a compreender o mundo a sua volta, os } \\
\text { animais, as plantas e o ser humano. }\end{array}$ \\
\hline P8 & $\begin{array}{l}\text { É importante porque fala, principalmente do meio ambiente e da } \\
\text { preservação. }\end{array}$ \\
\hline P9 & $\begin{array}{l}\text { Aprender Ciências é importantíssimo para os nossos alunos, porque } \\
\text { tem relação com a nossa qualidade de vida e com o nosso meio } \\
\text { ambiente. }\end{array}$ \\
\hline P10 & $\begin{array}{l}\text { Aprender Ciências é importante porque fala sobre o meio ambiente e } \\
\text { como devemos preservá-lo. }\end{array}$ \\
\hline
\end{tabular}

Fonte: Autoria própria (2019).

A prevalência dessa noção de $A C$ nas falas das professoras pode ser fruto da relação que elas estabelecem com os conteúdos de Ensino das Ciências, sem que consigam romper com uma visão de "senso comum" sobre o que seja a atividade científica, o que faz com que ela seja considerada em sua dimensão instrumental, puramente, sem as complexas conexões com os outros campos do conhecimento e com a sociedade mais ampla.

Para 30\% das entrevistadas, o ensino em Ciências é importante para a tomada de decisão e para o enfrentamento dos problemas de ordem científica. Isto pode ser observado nas informações obtidas de P2, P3 e P5 (Quadro 7) ao relatar que esse ensino ajuda a desenvolver o intelecto (raciocínio lógico) sobre o 
mundo e a natureza, ao envolver os alunos com problemas reais e que sejam conscientes de seus atos ou seja com tomada inteligente de ação e enfrentamento dos problemas de ordem natural ou social.

Quadro 7 - Classificação das falas, segundo os parâmetros de AC Cívica

\begin{tabular}{|c|c|}
\hline Professoras & Alfabetização Científica Cívica \\
\hline P2 & $\begin{array}{c}\text { (...) Aprender a desenvolver seu cérebro ou intelecto sobre o mundo e } \\
\text { a natureza (...) }\end{array}$ \\
\hline P3 & $\begin{array}{c}\text { (...) incentivar o aluno a buscar leitura para descobrir a pesquisa e fazer } \\
\text { registro de suas discussões, descobertas e não somente em Ciências, } \\
\text { mas pelo pensar, pelo pensamento lógico, partindo de atividades } \\
\text { práticas que tem envolvimento com problemas reais (...) }\end{array}$ \\
\hline P5 & $\begin{array}{c}\text { (...) O objetivo é formar adultos conscientes de seus atos no meio em } \\
\text { que vivem. }\end{array}$ \\
\hline
\end{tabular}

Fonte: Autoria própria (2018).

A progressiva exigência de uso e interpretação de conhecimentos e de informações científicas nas diferentes dimensões da vida cotidiana requer uma reflexão maior com relação à noção de AC Cívica por parte dos professores no momento de seu planejamento, pois, saber ler e interpretar escritos científicos, saber fazer interferências em decisões e expressar diferentes ideias, saber argumentar e compreender as limitações da Ciência são imperativos para a construção de uma sociedade mais justa, para o combate à precária escolarização da nossa população e para permitir às novas gerações a conquista de uma fortalecida base feita de recursos cognitivos.

Com relação à AC Cultural, percebeu-se que, para $20 \%$ das entrevistadas, essa importância deve se estender para esse nível, ou seja, como um aprimoramento de cultura científica (Quadro 8), como citado por P1 e P3, despertando o interesse e a curiosidade nos alunos pela área.

Quadro 8 - Classificação das falas, segundo os parâmetros de AC Cultural

\begin{tabular}{|c|c|}
\hline Professoras & Alfabetização Científica Cultural \\
\hline P1 & (...) despertar a curiosidade pelas tecnologias. \\
\hline P3 & $\begin{array}{c}\text { (...) desenvolver a leitura e a escrita, tudo isso, a meu ver, é para } \\
\text { descobrir a pesquisa, mas não somente em Ciências, mas em todas as } \\
\text { áreas do conhecimento. }\end{array}$ \\
\hline
\end{tabular}

Fonte: Autoria própria (2018).

Nas respostas de P3 foram observadas as três noções de alfabetização científica: a Prática, representada como os conhecimentos mínimos em Ciências para resolver problemas práticos do cotidiano, a Cívica, como o desenvolvimento do raciocínio lógico e no envolvimento com problemas relacionados às Ciências e, por fim, a Cultural, aqui descrita, como um meio para incentivar os alunos à leitura e à pesquisa como forma de ampliar seus conhecimentos sobre aquilo que estão aprendendo. A professora P3 se diferencia, das demais professoras entrevistadas, por possuir uma série de formações continuadas, que a possibilitou fazer essa interpretação sobre a importância do ensino de Ciências na escola.

Uma questão do questionário teve como objetivo identificar se os estes poderiam influenciar sobre suas percepções sobre o ensino de Ciências. 
As respostas se distribuíram da seguinte forma: 50\% frequentaram algum curso de capacitação nos últimos 12 meses, sejam eles, oficinas de trabalho, seminários, pós-graduação, etc. Porém, aproximadamente metade dos que frequentaram as formações não souberam nomear qual curso participaram.

Dentre as atividades de desenvolvimento profissional que se destacaram nas respostas obtidas, aquelas ofertadas pela SME em parceria com a Universidade Federal do Paraná (UFPR), ou seja, atividades como a visita ao museu de anatomia, curso sobre solos, astronomia, paleontologia, fazenda escola e os cursos de pós-graduação stricto sensu.

Outras atividades citadas foram o mestrado ofertado pelo Programa de PósGraduação em Formação Científica, Educacional e Tecnológica (PPGFCET), da Universidade Tecnológica Federal do Paraná (UTFPR), o Seminário Municipal de Educação Ambiental que ocorre anualmente, visita ao planetário, oficinas no Zoológico Municipal de Curitiba, a Semana de Estudos Pedagógicos (SEP) e o Programa Nacional de Alfabetização na Idade Certa (PNAIC).

A parceria entre a SME e as universidades (UTFPR e UFPR) para a realização de cursos de formação continuada é uma estratégia para os professores se apropriarem de teorias e metodologias que os auxiliem no desenvolvimento de práticas investigativas, como aponta o Currículo Municipal. Essa parceria também sinaliza que apesar de não se expressar em suas concepções, é possível que os professores possam estar desenvolvendo outras noções de AC.

Ao serem questionadas sobre como avaliavam os cursos de formação continuada ofertados pela SME, predominantemente, as professoras os avaliam positivamente (Figura 1). De acordo com as participantes, os cursos são de boa qualidade e suprem suas necessidades formativas.

As que consideram que são necessárias melhorias, são em menor número, havendo relatado a necessidade de maior abrangência nos conteúdos. Outras professoras consideraram os cursos de formação continuada repetitivos e, numa escala menor, algumas professoras os consideraram fracos. Já as professoras que responderam "sem opinião" e "outros" justificaram essas respostas pelo fato de não terem participado desses cursos.

Figura 1 - Gráfico referente à opinião das professoras sobre os cursos de capacitação oferecidos pela RME

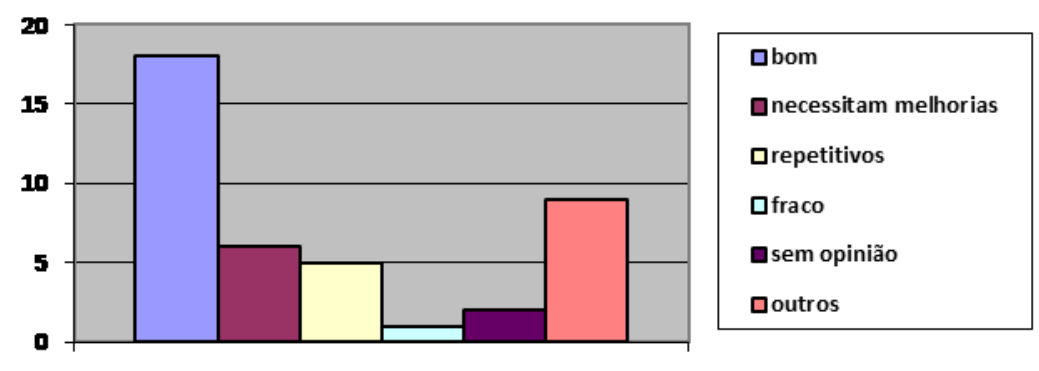

Fonte: Autoria própria (2018).

Alguns fatores levantados nos questionários ajudam a compreender os motivos da ausência dessas profissionais nos cursos ofertados pela SME, dentre eles, o fechamento do prédio do Centro de Formação Continuada da Prefeitura 
Municipal de Curitiba ocorrido em 2017, pois, por se tratar de uma localização central, facilitava-se o acesso aos cursos oferecidos pela secretaria.

\section{CONSIDERAÇÕES FINAIS}

O Currículo Municipal de Curitiba propõe concepções de Ensino de Ciências voltadas ao desenvolvimento da alfabetização científica, na perspectiva do letramento científico que, além de favorecer a compreensão do funcionamento da natureza, preza pelas implicações socioculturais resultantes das intervenções científicas e tecnológicas no dia-a-dia das pessoas.

Apesar de a importância de se ensinar Ciências na escola ser reconhecida pelas participantes da pesquisa, infelizmente, os cidadãos brasileiros apresentam muitas dificuldades na compreensão dos fenômenos científicos, como mostra os dados apresentados no sumário executivo do Indicador de Letramento Científico (GOMES, 2015). De acordo com esse documento, que visa determinar diferentes níveis de domínio das habilidades de letramento e no uso da linguagem e dos conceitos do campo da Ciência no cotidiano dos brasileiros, $48 \%$ dos brasileiros entrevistados estão no nível 2, ou seja, apresentam Letramento Científico Rudimentar. Esse nível mostra que o sujeito resolve problemas que envolvam a interpretação e a comparação de informações e conhecimentos científicos básicos apresentados envolvendo temáticas presentes no cotidiano, como por exemplo, riscos e benefícios à saúde ou questões que envolvam o meio ambiente.

Deste modo, é importante que os professores ultrapassem suas concepções de $A C$ prática para as outras noções, $A C$ cívica e $A C$ cultural, e proporcionem a construção do conhecimento científico em uma perspectiva crítica, levando em conta a compreensão dos conceitos científicos em seus aspectos de interdependências, sem deixar de lado o papel da instrumentalização do estudante, através do conhecimento produzido na construção da cidadania.

Os resultados, também mostraram que as percepções apresentadas pelas professoras dos anos iniciais sobre o ensino de Ciências, são parecidas com as declaradas pelos professores dos anos finais do Ensino Fundamental, ou seja, percebe-se em ambas as bases visões predominantemente propedêuticas, isto é, com vistas ao suprimento de necessidades básicas de conhecimento sobre um determinado assunto, porém, ainda insuficiente para o desenvolvimento da AC. Assim, ela caminha devagar nas escolas como mostra os estudos de Lustosa, Alves, Araújo e Geglio (2016) e Vitorino (2010).

Em linhas gerais, pode-se perceber que as professoras entrevistadas pouco desenvolvem as outras proposições do Currículo Municipal de Curitiba relativas à alfabetização científica em suas dimensões cívica e cultural, havendo uma predominância, portanto, da dimensão prática, enquanto expressão de uma série de fatores, tais como a formação inicial generalista, o modo de organização dos livros didáticos para estes anos de escolaridade, baixa adesão às formações continuadas, etc.

Os dados construídos nesta investigação evidenciam um ponto crucial que é a importância da formação continuada, visto que não é fácil para um professor generalista se apropriar de todas as áreas do conhecimento, como forma de se 
reformular as concepções e práticas docentes para que se obtenha um avanço na qualidade deste ensino.

No entanto, para além da necessidade de mais programas e cursos de formação na área servindo de incentivo para uma melhor formação desses profissionais, necessita-se, também, que estes participem destas formações e, consequentemente, os mesmos possibilitarão aos seus alunos um conhecimento científico e tecnológico mais acurado.

Esse resultado sinalizou, também, a necessidade de se incluir em programas de formação continuada, além de aspectos metodológicos, aspectos conceituais e princípios científicos abordados no currículo de Ciências e que compõem a programação da SME. O desconhecimento das concepções e da produção acerca do ensino e aprendizagem de Ciências é um dos maiores entraves na busca por mudanças na prática docente nesse nível de ensino.

Na SME existe um programa de formação continuada que dá subsídios aos professores das escolas municipais com referenciais teóricos, reflexões acerca de concepções metodológicas e práticas de ensino voltadas a alfabetização científica na perspectiva do letramento. Além das reuniões, permanências concentradas e cursos de formação continuada, a SME fornece material de apoio para auxiliar os professores em suas mediações, como, por exemplo, os cadernos pedagógicos de Ciências.

Os resultados apresentados apontam para uma necessidade de se repensar os objetivos e as práticas desenvolvidas no ensino de Ciências nos anos iniciais do Ensino Fundamental para que se caminhe dentro do processo de alfabetização científica e, assim, sejam preenchidas as lacunas que existem na compreensão dessa abordagem.

Ressalta-se, por fim, a necessidade de que outras pesquisas sejam desenvolvidas nesta temática e de que o processo de formação docente seja contínuo, por meio de formas de aproximações teórico-metodológicas levandose em consideração o cotidiano escolar, suas necessidades e a experiência profissional docente. 


\title{
Scientific literacy in science teaching in the early years of elementary school: perceptions of teachers of municipal school system of Curitiba
}

\begin{abstract}
This paper presents the results of a research conducted with teachers of the early years of elementary school in public schools in Curitiba, Paraná, Brazil, on the theme of scientific literacy, which, according to Shen (1975), enables a greater public understanding of science and a demystification of scientific knowledge so that people can use it in their daily lives. These assumptions are being addressed by the Elementary School Curriculum 1st to 9th grade, Volume IV, referring to the Natural Sciences, of Curitiba City Hall, which is the document that guides the school plans for Natural Sciences teachers of the municipal public schools. However, beyond what is presented in the official document, it is necessary to know what the teachers who work in these schools think. Thus, this research, qualitative, descriptive and interpretive in nature, was guided by the following research problem: what are the teachers' perceptions about the teaching-learning process of Natural Sciences from the perspective of scientific literacy? As methodological paths, we used questionnaires $(n=45)$ and semi-structured interviews $(n=10)$, which aimed to investigate teachers' perceptions about the teaching-learning process of Natural Sciences for the early years of elementary school. The results of the research showed that the conception of science of the research participants tended towards the notion of practical scientific literacy, from the perspective of science teaching focused on basic understandings of the area, such as the use of scientific concepts in daily life and preservation of the environment; relating science learning to basic needs such as food, health and improving quality of life. The other propositions of the Municipal Curriculum, that is, those related to scientific literacy in its civic and cultural dimensions are less developed. Therefore, there is a predominance of the practical dimension, as an expression of a series of factors, such as, for instance, the generalist initial formation, the mode of organization of textbooks for these years of schooling, low adherence to continuing education, among other aspects. The data collected in this research point to a need for rethinking the objectives and practices developed in science teaching in the early years of elementary school, so that it is possible to develop a process of scientific literacy and, thus, fill the gaps that exist in understanding this approach. It is also emphasized the need for research and continuous process of teacher education as a way of theoretical and methodological approaches taking into account the school reality, its needs and the teaching professional experience.
\end{abstract}

KEYWORDS: Natural Sciences. Scientific literacy. Curriculum. Teaching-learning. 


\section{AGRADECIMENTOS}

Agradecemos às professoras da Rede Municipal de Educação de Curitiba participantes desta pesquisa por compartilharem suas experiências educacionais.

\section{REFERÊNCIAS}

BOCHECO, O. Parâmetros para a abordagem de evento no enfoque CTS. 2011. 165 f. Dissertação (Mestrado em Educação Científica e Tecnológica) - Centro de Ciências da Educação, Universidade Federal de Santa Catarina, Florianópolis-SC, 2011.

BOGDAN, R.; BIKLEN, S. Investigação qualitativa em educação: uma introdução à teoria e aos métodos. Porto: Porto Editora, 1994.

BRASIL. Base Nacional Comum Curricular. Brasília; MEC, 2017.

BRICCIA, V.; CARVALHO, A. M. P. Competências e formação de docentes dos anos inicias para a educação científica. Ensaio: Belo Horizonte, v. 18, n.1, p.1-22, 2016.

CRESWELL, J. W. Projeto de pesquisa: métodos qualitativo, quantitativo e misto. Porto Alegre: Artmed, 2007.

CURITIBA, Prefeitura Municipal de. Currículo do Ensino Fundamental - Ciências: 1음 ao ano. Curitiba, 2016.

DECLARAÇÃO DE BUDAPESTE. Declaración sobre la ciência y el uso del saber científico, 1999.

GOMES. A. S. L. Letramento científico: um indicador para o Brasil. São Paulo: Instituto Abramundo, 2015.

LAUGKSCH, R. C. Scientific literacy: a conceptual overview. Science Education, London, v. 84, n. 1, p. 71-94, 2000.

LORENZETTI, L. Alfabetização científica nas séries iniciais. 2000. 143 f.

Dissertação (Mestrado em Educação) - Centro de Ciências da Educação, Universidade Federal de Santa Catarina, Florianópolis-SC, 2000.

LORENZETTI, L. E DELIZOICOV, D. Alfabetização científica no contexto das séries iniciais, Ensaio, Belo Horizonte v.3, n.1, p. 37-50. 2001.

LUSTOSA, M. S.; ALVES, R. M. M.; ARAÚJO, M. S. M.; GEGLIO, P. C. Percepções de professores sobre o ensino de ciências nos anos finais do Ensino Fundamental. In: III CONEDU: Congresso Nacional de Educação, 2016, Campina Grande-PB. Anais [...] Campo Grande- PB, 2016. 1986. 
SANTOS, W. L. P; MORTIMER, E. F. Tomada de decisão para a ação social responsável no ensino de ciências. Ciência \& Educação, v. 7, n. 1, p.95-111, 2001.

SASSERON. L. H. Alfabetização Científica, ensino por investigação e argumentação: relações entre Ciência da natureza e escola. Ensaio: Belo Horizonte, v.17, n. especial, p.49-67, 2015.

SASSERON, L. H.; CARVALHO, A. M. P. Construindo argumentação na sala de aula: a presença do ciclo argumentativo, os indicadores de Alfabetização Científica e o padrão de Toulmin. Ciência e Educação, v. 17, p. 97-114, 2011.

SHEN, B. S. P. Science literacy. American Scientist, v. 63, p. 265-268, maio, 1975.

SILVA, E. T; SÁ, R. A; BATINGA, V. T. S. A resolução de problemas no Ensino de Ciências baseadas numa abordagem investigativa. ACTIO, Curitiba, v. 4, n. 2, p. 169-188, 2019. Disponível em: https://periodicos.utfpr.edu.br/actio.

SIEMSENS, G.H. O ensino de astronomia numa abordagem interdisciplinar no Ensino Médio: potencialidades para a promoção da alfabetização científica e tecnológica. 2019. 247 f. Dissertação (mestrado). Universidade Federal do Paraná, Curitiba-PR, 2019.

SOLINO, A. P.; FERRAZ, A. T.; SASSERON, L. H. Ensino por investigação como abordagem didática: desenvolvimento de práticas científicas escolares. In: XXI Simpósio Nacional de Ensino de Física. Anais [...]. p. 1-6, 2015.

VITORINO, M. A. Concepção do ensino de ciências entre os professores do ensino fundamental II em escolas da rede pública e privada de Campina Grande-PB. (Monografia) Campina Grande: Universidade Estadual da Paraíba, 2010.

Recebido: 25.ago. 2019

Aprovado: 04 nov. 2019

DOI:10.3895/actio.v4n2.3527

Como citar:

FABRICIO, L; MARTINS, A. A. Alfabetização científica no ensino de ciências nos anos iniciais do ensino fundamental: percepções de professores da rede municipal de ensino de Curitiba. ACTIO, Curitiba, v. 4, n. 3,

p. 594-609, set./dez. 2019. Disponível em: https://periodicos.utfpr.edu.br/actio. Acesso em: XXX

Correspondência:

Lucimara Fabricio

Rua Theolindo Franco da Cruz, 53, Cidade Jardim, São José dos Pinhais, Paraná, Brasil.

Direito autoral: Este artigo está licenciado sob os termos da Licença Creative Commons-Atribuição 4.0

Internacional.

(c) (i) 